BULL. AUSTRAL. MATH. SOC.

VOL. $3(1970), 287-288$.

\title{
On regular semigroups whose idempotents form a semigroup: Addenda
}

\author{
T. E. Hall
}

The results in the first parts of Theorems 2 and 3 of the paper in the title (see [2]) have been previously obtained by B.M. Schein in Theorem 1.12, page 299 [4], and in Proposition 1.13 (combined with the last paragraph of page 300) [4], respectively. To deduce the first part of Theorem 2 [2] from Theorem 1.12 [4] one merely uses the fact that a binary relation $R$ on a set $X$ satisfies $R R^{-1} R \subseteq R$ if and only if it satisfies: $R(x) \cap R(y) \neq \square$ implies $R(x)=R(y)$, for any $x, y \in X$ (see Proposition 9, page 132 [3]).

Conversely, one can deduce the mentioned results in [4] from those in [2] by observing that all the regular elements in any semigroup form a subsemigroup if (and clearly only if) the product of each pair of idempotents is a regular element, in particular when all the idempotents form a subsemigroup (from Theorem 2.4, page 49 [1]).

The equivalence of (i) and (ii) in Result 1 [2] (cited as due to N.R. Reilly and H.E. Scheiblich) has also been obtained by B.M. Schein in Theorem 1.10, page 298 [4].

\section{References}

[1] A.H. Clifford and G.B. Preston, The algebraic theory of semigroups (Math. Surveys 7(I), Amer. Math. Soc., Providence, Rhode Island, 1961).

Received 27 July 1970. The author is grateful to B.M. Schein for supplying the references [3] and [4]. 
[2] T.E. Hall, "On regular semigroups whose idempotents form a subsemigroup", BulZ. Austral. Math. Soc. 1 (1969), 195-208.

[3] J. Riguet, "Relations binaires, fermetures, correspondances de Galois", Bull. Soc. Math. France 76 (1948), 114-155.

[4] B.M. Să̌n, [= B.M. Schein], "On the theory of generalized groups and generalized heips" (Russian), Theory of semigroups and app 2 . I (Russian), 286-324, (Izdat. Saratov. Univ., Saratov, 1965).

Department of Mathematics,

University of Stirling,

Scotland. 